\title{
A Qualitative Research on Teachers' Experience in Operating High School Curriculum
}

\author{
Sahoon Kim1)
}

\begin{abstract}
The purpose of this study is to derive various issues related to the operation of high school elective courses. In particular, this study examined the efforts of teachers and investigated ways to support them. To this end, Focus Group Interview (FGI) was conducted in this study. The main research questions were as follows. First, what are the difficulties and improvements in the elective course management? Second, what are the efforts of schools to expand their electives? Third, what are the important challenges that need to be addressed to expand elective courses? Based on the result of the study, experts answered that the high school curriculum organization was closely related to the college entrance exam. In other words, in order to organize a variety of elective courses, the university admission system needs to accept the results of the elective courses. Indeed, school culture was an important issue in curriculum organization.
\end{abstract}

Keywords: Elective Curriculum, Electives, High School Curriculum, Teacher Education, Korean High School Curriculum

\section{Introduction}

Various studies are being attempted to examine the educational phenomenon in a fusion in various situations[1-4]. It is interesting to look at the phenomena we can see on a daily basis educationally. For example, a traveler may travel by selecting destinations on his own, or may travel to destinations tied to a tourist package. Each has its pros and cons. The former can make travel plans that take into account individual tastes. However, if a traveler wants to visit an unpopular tourist destination, transportation can be difficult. Conversely, in the latter case, travelers can efficiently explore popular courses. But because of that, some tourist destinations will be boring to them. This situation is similar to that of school.

In Korea, schools have traditionally been accustomed to running the curriculum set by the

Received(May 09, 2020), Review Result(1st: June 27, 2020, 2nd: August 17, 2020), Accepted(September 25, 2020)

1) (Professor) 02450 Dept. Education, HanKuk Univ. of Foreign Studies, Imun-dong, Dongdaemun-gu, Seoul, Korea email: kimsh@hufs.ac.kr

This study was conducted by revising and deepening some of the authors' writings in the report of "Kim, S., Park, J., and Jeon, H. 2019 High School Student-Centered Curriculum Organization and Operation Status Survey-Student Course Selection Status" 
state. The students had taken classes according to the curriculum set by the school. Accordingly, the school operated the curriculum efficiently, and the timetable was organized around so-called'popular subjects'.

Recently, there is an active movement to change such a uniform curriculum. In a diversified society, students have become more focused on the process of making their own knowledge rather than learning uniform knowledge.

In vocational high schools, subject selection is relatively free. Therefore, studies on the relationship between vocational and technical subject selection and student achievement have been conducted[5][6]. In general, compared to college students, high school students did not voluntarily choose subjects[7].

The purpose of this study is to derive various issues related to the operation of high school elective courses. In particular, this study looked at the efforts of schools and teachers, and also looked at the efforts to support the expansion of elective subjects. To this end, this study performed Focus Group Interview(FGI).

\section{Research Method}

In this study, Focus Group Interview(FGI) was conducted for curriculum experts and high school teachers. Interviews were about high school elective teaching methods, school efforts, and general issues. FGI was held in mid-November and late November. The interview used semi-structured questionnaires. The main interview protocols were as follows.

First, what are the difficulties and improvements in the elective course management?

Second, what are the efforts of schools to expand their electives?

Third, what are the important challenges that need to be addressed to expand elective courses?

\section{Results}

\subsection{Implications for Practical Subject Guidance}

Teachers' and experts' opinions on how to improve students' subject selection satisfaction are as follows. 


\subsubsection{Subject Selection Required by the Subjective Choice of the Student}

While a student's electives may be related to the desired career and aptitude, many students still choose subjects that favor college admissions. This seems to apply to both students preparing for Total Student Report Mode (RATSRM) and K-SAT (KSAT).

Standards for student subject selection were established. It was grade. Of course, there are some friends who are convinced of their career. There will be many meaningful subjects for those friends. However, students are more sensitive to grades than we expected. Have you ever heard an Arabic lotto? Students choose Arabic because the K-SAT level will increase if they choose Arabic. Students are not interested in what education policy is aiming for. They look for how to get good grades in the changed policy. - Expert 4

While students' careers continue to change, students should stick to their own careers as they can be penalized by RATSRM. With so much emphasis on career choices in college admissions, students are forced to tailor their careers to their aptitudes. In high school, career paths can change and of course they should. Students are afraid of career changes. Once a student has decided on a career path, it is recorded. I think students should continue to take courses that fit their careers. -Expert 1

Students often choose courses based on their friends. They are not interested in class, but come to class with friends. Even talking with a group of friends, the quality of the class deteriorated. Teachers are required to provide very specific guidance on subject selection. In addition, the school must inform the student that it is responsible for it. -Expert 3

Korean curriculum aims to explore careers in middle school and design careers in high school. However, career design is not yet familiar to many students. Expanding student-centered electives is a policy that can significantly improve the field of high school education. However, if students cannot make independent choices, the effect may not be significant.

To compensate for this problem, it is necessary to strengthen students' career education. Career education may not be successful as a superficial introduction to a variety of careers. Introducing the curriculum roadmap as a whole, such as going on to a career, finding a career, and a series of related subjects, will be a way to induce students' practical choices. 


\subsubsection{Need to Strengthen the Responsibility of Choice through Detailed Course Guidance}

The student-selected curriculum could be a way to overcome conventional teacher-centered instruction. In addition, students might be engaged in a variety of unique curriculum activities, ranging from the preparation stage to the execution and termination stages, without being tied to the exam. To do this, students must choose a subject through voluntary decision-making, feel that it is meaningful to act in a class of her own choosing according to his will. Indeed they should demonstrate their own abilities through the activities.

The biggest advantage of the elective course is that the students voluntarily participate. It is quite different from the traditional class. Students are more responsible than they think about the subjects they choose. This is definitely felt at the beginning of the semester ... Sometimes, the motive may be weakened from the middle. At this time, the students should be ventilated again. "It's your chosen subject ... And it's the class method you chose". Then I felt that the students were taking responsibility and the motivation to participate in the class is rising. Expert 1

Students participate in elective courses, especially those with a small number of students. Because of the process-oriented evaluation. Students like the style that suits them because they know that they are taught and evaluated in the way they want. Also, the sense of responsibility works better for high school students than I thought. So, I think it's important to be as specific as possible about pre-class lessons and make them feel that they have chosen it. -Expert 2

The content included in guiding the subject was the nature of the subject, the content of the subject, the relationship with the job, and the relationship with other subjects. Nevertheless, the students showed considerable interest in the teaching method of the subject above all else. In student-centered classes, student participation is essential. Students are very satisfied with the subject they deliberately choose. If the subject is guided in as much detail as possible, it will be of great help to students to select or judge the details.

\subsubsection{Necessity of Establishing a System for Career Guidance}

As a result of the FGI, various experts emphasized that systematic support measures should be prepared for career guidance. 
In the high school credit system, it means that the school will be eventually operated like a university. Why do you think that students need a homeroom teacher? Professors of universities don't know what students like and do not spent much time for students. Isn't it right to remove the role of homeroom and run a career guidance organization for each subject, such as a university? -Expert 1

It is difficult for a career counselor to keep track of a student's entire career. Career counseling itself relies on superficial documentation. There is very little you can do other than pass on the information. It's actually impossible to entrust all career guidance to a career counselor. -Expert 4

There are curriculum advisors abroad. The role of the curriculum advisor is to consider students' grade and display course loads for similar students. It also guides students through college and career links. It also serves as a guide to provide comprehensive information on related curriculum, such as insufficient credit for graduation. Korea should also consider how to activate curriculum consultants and prepare for qualifications. This qualification seems to require a separate discussion of professional training courses and requirements. -Expert 6

In the high school credit system, schools will eventually run like colleges. Why do I need a homeroom teacher? University professors spend time together without knowing what their students like. Isn't it correct to eliminate the role of homeroom teacher and run a career guidance organization for each subject, such as college? -Expert 1

It is difficult for a career counselor to track a student's entire career. Career counseling itself relies on superficial documentation. There is very little you can do other than conveying information. With so many things to do, it is practically impossible to leave all career guidance to a career counselor. -Expert 4

There are curriculum advisors abroad. The role of the curriculum advisor is to consider student grades and display course loads for similar students. It also guides students through college and career links. It also serves as a guide to provide comprehensive information on related curriculum, such as insufficient credit for graduation. Korea should also consider how to activate curriculum consultants and prepare for qualifications. This qualification seems to require a separate discussion of professional training courses and requirements. -Expert 6

Experts argued that practical guidance of students is difficult only with a homeroom teacher or career counselor. On the other hand, the role of the curriculum guide was suggested to 
modify the role of teachers or to strengthen the capabilities of career counselors. Experts have emphasized the need for information on defect management, academic information and career paths.

\subsection{School-level Application Direction}

\subsubsection{Forming a School Culture to Open Elective Courses}

As a result of FGI, various experts suggested that the school culture needs to be improved.

To change perceptions, school culture must change. It is unlikely that the culture will change in a year or two. It takes at least 4 to 5 years for the school culture to settle to some extent. By the way, after that I have to go to another school. I don't know if other principals will take this seriously. The principal at this school received full support, so I was still able to persuade other teachers. But it's only a matter of time before I keep getting bullied at other schools (laughs). After all, the will of the principal is important, but it is also important to change the school culture. -Expert 2

In fact, our school was a pilot school, so it wasn't that difficult for our members. The problem is after the pilot period. After this experience the school will have to do other work, but there is no guarantee that this experience will last. Like other teachers, the will, communication and support of the principal is important. But ultimately, the change in school culture is paramount. -Expert 1

When it comes to the opening of elective courses, the positions of teachers were divided in favor and opposite. Teachers, who believe that course selection is a way to expand student career options and improve practical education management, agreed to open elective courses. They actively learned how to read the curriculum, encouraged available courses, and helped students enroll in those courses. In addition to the transfer of existing subject knowledge, teachers who emphasized various career-related experiences also emphasized the importance of elective subjects. On the other hand, the opposing teachers thought that the selection of high school subjects were greatly influenced by college entrance examinations. They thought that opening a variety of subjects was the inefficiency of school management.

Meanwhile, many teachers still feel a considerable burden on the diversity of course 
offerings. This suggests the need to revitalize a teacher community culture. It is necessary to devise a plan to connect subjects in 3 to 5 units using the teacher's collective intelligence. In addition, it is necessary to devise a method of designing a common curriculum and classes and conducting joint classes.

\subsubsection{Overworked Teachers}

Diversification of elective courses has been found to increase the burden on teachers. The burden of teachers is that, as the number of subjects taking the written test increases, the number of subjects increases, and the burden of administrative work increases with various classes.

The term 'administrative work' needs to be changed to convey the word 'reducing the teacher's administrative work' to the outside world. In addition to organizational tasks such as formal document processing, teacher management tasks include areas close to the student, such as the student's student record. Writing down student records that need to be made more detailed than before is considered to be the administrative work of the teacher, and the outside view this as administrative. -Expert 1

As suggested above, it can be seen that when teachers teach different subjects, the questionnaire of the written test in various subjects leads to overwork. In particular, in the context of high parental dissatisfaction with school performance and pressure on fairness of evaluation, the paper-based exams in teachers have accumulated a lot of fatigue.

On the other hand, it has been found that teachers suffer from excessive administrative work because administrative work realistically includes student management and student records in addition to paperwork performed within the organization. Teachers have always had a demand to reduce administrative work. In particular, as the student's choice of subject becomes diversified, the workload may increase rapidly. In consideration to this, measures to reduce teachers' work need to be prepared.

\section{Conclusion}

This study performed an in-depth analysis of phenomena occurring in student-centered curriculum management. As a result, the following conclusions were drawn.

Teachers value the environment in which they operate. In particular, teachers said that it was not easy to operate elective courses due to college admission. Ensuring the student's choice wasn't easy as long as there were subjects that were important to the college entrance 
exam. On the other hand, experts argued that the number of elective courses could be increased by comprehensively considering students in addition to the KSAT and expanding the method of entering college.

In other words, expansion of elective courses cannot be considered separately from college entrance examinations. This study makes no claims about what would be good for college entrance examination methods. However, educational policy makers should be aware that the method of admission to college affects the expansion of electives. It is necessary to expand the college entrance examination method as a reward for self-selection so that students can increase their elective courses.

In addition to this, the principal's will and efforts are important, but it is also important to improve the overall school culture. Teachers cannot stay in one school for a long time. Individual teacher efforts do not successfully expand electives. Continuous cultural change should appear throughout the school.

In particular, there were many opinions that the reduction of teachers' work was important. Teachers want to run a variety of electives, but they are too responsible. They have to produce many exams to teach a variety of subjects, and to write many report cards to teach a variety of subjects. This responsibility prevents teachers from diversifying their electives. Education policymakers need to prepare a variety of ways for teachers to focus on their classes.

\section{References}

[1] J-Y. Lim, Y-M. Lee, Direction and Challenges of High Skills Vocational Education and Training Policies in Response to Future Social Changes, International Journal of Computer Science and Information Technology for Education, (2016), Vol.1, No.1, pp.7-14, http://dx.doi.org/10.21742/IJCSITE.2016.1.1.02.

[2] S-Y. Chun, W. Grift, Birth of University: Different Stories in Asia and Europe, International Journal of Computer Science and Information Technology for Education, (2016), Vol.1, No.1, pp.23-28, GVPress, http://dx.doi.org/10.21742/IJCSITE.2016.1.1.04.

[3] S. Hong, S. Bae, Factors Related to Test Anxiety for Studying TOEIC among College Student of Health Affiliated Educations, International Journal on Consulting Psychology for Patients, (2018), Vol.2. No.2, pp.19-26, http://dx.doi.org/10.21742/IJCPP.2018.2.2.04

[4] S. Kim, Comparative Analysis of United States and South Korean High School, Asia-Pacific Journal of Educational Management Research, (2020), Vol.5, No.2, pp.35-40.

[5] R. Bozick, B. Dalton, Balancing career and technical education with academic coursework: The consequences for mathematics achievement in high school, Educational Evaluation and Policy Analysis, (2013), Vol.35, No.2, pp.123-138. 
Vol.6, No.10, October 31 (2020), pp.181-189 http://dx.doi.org/10.47116/apjcri.2020.10.14

[6] S. W. Hemelt, M. A. Lenard, C. G. Paeplow, Building bridges to life after high school: Contemporary career academies and student outcomes, Economics of Education Review, (2019), Vol.68, pp.161-178.

[7] K. M. Galotti, V. A. Umscheid, Students Choosing Courses: Real-Life Academic Decision Making, The American Journal of Psychology, (2019), Vol.132, No.2, pp.149-159. 